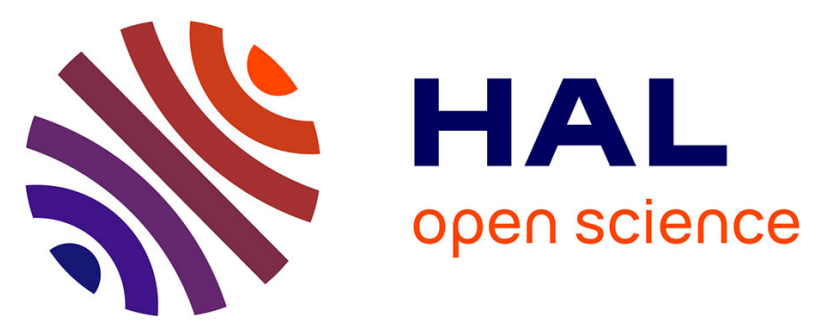

\title{
A stochastic growth model of grapevine with full interaction between environment, trophic competition and plant development.
}

Benoit Pallas, Cedric Loi, Angélique Christophe, Paul-Henry Cournède, Jérémie Lecoeur

\section{To cite this version:}

Benoit Pallas, Cedric Loi, Angélique Christophe, Paul-Henry Cournède, Jérémie Lecoeur. A stochastic growth model of grapevine with full interaction between environment, trophic competition and plant development.. Third International Symposium on Plant Growth Modeling, Simulation, Visualization and Applications (PMA09), Nov 2009, Pékin, China. pp.95-102. inria-00546291

\section{HAL Id: inria-00546291 \\ https://hal.inria.fr/inria-00546291}

Submitted on 14 Dec 2010

HAL is a multi-disciplinary open access archive for the deposit and dissemination of scientific research documents, whether they are published or not. The documents may come from teaching and research institutions in France or abroad, or from public or private research centers.
L'archive ouverte pluridisciplinaire HAL, est destinée au dépôt et à la diffusion de documents scientifiques de niveau recherche, publiés ou non, émanant des établissements d'enseignement et de recherche français ou étrangers, des laboratoires publics ou privés. 


\section{A stochastic growth model of grapevine with full interaction between environment, trophic competition and plant development.}

\author{
Benoît Pallas \\ Ecole Centrale de Paris \\ pallas@supagro.inra.fr \\ Paul-Henry Cournède \\ Ecole Centrale de Paris \\ paul-henry.cournede@ecp.fr
}

\author{
Cédric Loi \\ Ecole Centrale de Paris \\ cedric.loi@ecp.fr
}

Jérémie Lecoeur

Montpellier-SupAgro

jeremie.lecoeur@supagro.inra.fr

\author{
Angélique Christophe \\ INRA-UMR LEPSE \\ christop@supagro.inra.fr
}

\begin{abstract}
Grapevine development is mainly determined by environmental factors whose effects are modulated by its complex topological structure. The trophic relationships between all the organs of the different axes appear to be the main underlying process which drive axis organogenesis in fluctuating environment. A new modelling approach is proposed based on GreenLab formalism in which axis organogenesis is controlled by stochastic processes according to trophic competition between the different axes. In this model, a water budget was also implemented to account for the effects of water depletion. The model was validated at organ and axis scales on a large range of environmental conditions in terms of photosynthetic active radiation, temperature and soil water supply. The efficiency of the model to simulate plant development at a detailed scale proved its ability to further analyse of the retroactions between plant development and the different environmental variables in order to improve crop management.
\end{abstract}

\section{Introduction}

Grapevine development is mainly determined by environmental factors such as temperature (through thermal time [1]) and abiotic stresses (e.g. soil water deficit [2]). Moreover, the source-sink relationships during plant development also modulate the vegetative and reproductive development [1], in relation with changes in trophic competition inside the plant [3]. The effects of all these factors on plant development have resulted in the development of diverse agronomic practices, such as pruning [4] or irrigation [5]. However, to improve these practices and increase our understanding of plant development in contrasting environments, modeling approaches appear useful and complementary to experiments.
Grapevine shoot is a modular branching system, with one primary axis and many secondary axes organized into a structure of three successive phytomer types (P0, P1 and P2). P0 phytomer bear no tendril or cluster. Phytomers bearing one tendril or cluster are classified as P1 or P2 phytomers depending on their positions with respect to the previous P0 phytomer [1]. Temperature determines the potential organogenesis of the axes [1], and trophic competition modulates their development [1]. The impact of trophic competition on axis organogenesis varies according to the type of axis. Primary axis appears almost insensitive to trophic competition. Secondary axes born by $\mathrm{P} 0$ phytomers are less affected than the ones born by P1 or P2 phytomer [1]. Soil water deficit reduces the photosynthetic activity of the plant [2] and in this way tends to have the same effect on plant development as an increase in trophic competition. Futhermore, soil water deficit also induces a signaletic regulation, which leads to reduce the potential organogenesis of the axes [6].

A model taking into account the effects of temperature and soil water deficit on shoot development have been proposed [2]. Besides, a first attempt to describe biomass fluxes in grapevine was made with GreenLab model [3]. This model proved effective for analyzing the relationships between plant functioning and plant development. However, in this approach, plant organogenesis was fixed and defined with no retroaction between trophic competition and organogenesis. Thus, it did not allow simulating the plant development in fluctuating environments. A formalization of the interactions between plant organogenesis and plant functioning in GreenLab model has been already done [7]. But these studies were purely theoretical with no confrontation with plant measurements. We propose in the present study, a new version of the grapevine model with stochastic organogenetic rules and probability distribution linked to temperature, trophic competition and water plant status. To assess pluriannual simulations this model includes reserve mobilization and storage. The results of the simulation of the model were compared to experimental data collected on two cultivars 'Syrah' 
and 'Grenache N.' submitted to different levels of photosynthetic active radiation (PAR) and soil water status (FTSW).

\section{Materials and methods}

\subsection{Model description}

General structure. GreenLab is a model which aims to calculate at each time step of the model total assimilate supply $(Q)$ and organ demand $(D)$. In GreenLab the $Q / D$ ratio was observed to be an adequate indicator of plant trophic status [7]. The aims of this present version was to input in the model relationships between $Q / D$ values at each growth cycle and organogenesis processes. Moreover, the influence of the plant water status on both organ demand and assimilate supply was also implemented in this version (Fig. 1).

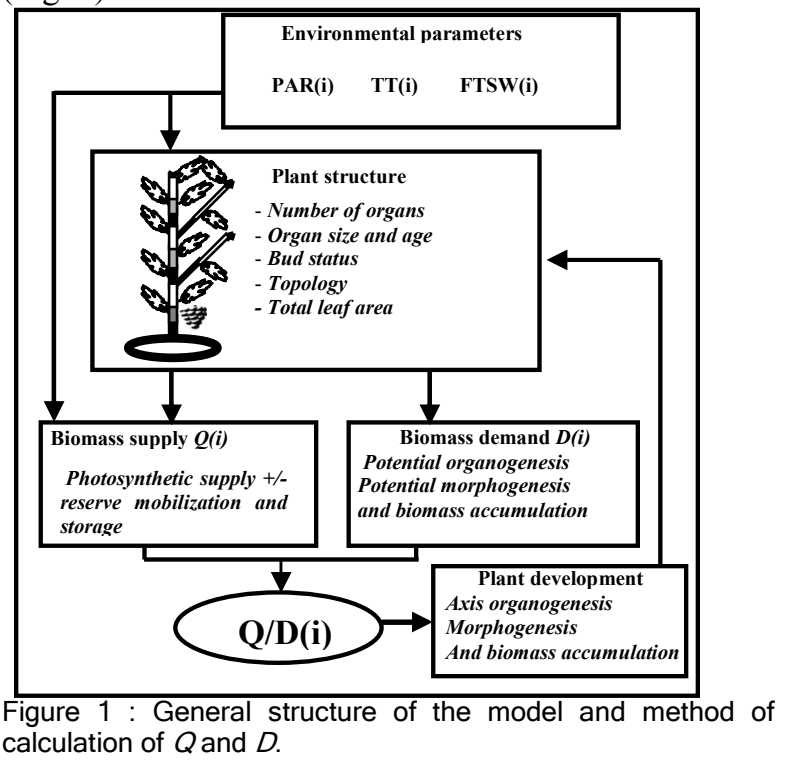

Plant topology. Grapevine shoot is composed of primary and secondary axes. The secondary axes can be separated into two types of axis depending on their observed behaviour [1]. Thus, three orders of physiological ages are implemented in the model, respectively for primary axis, P0 secondary axes and P1-P2 secondary axes (i.e. secondary axes born respectively by $\mathrm{P} 0$ or $\mathrm{P} 1-\mathrm{P} 2$ phytomers). On all the axes, the P0 phytomers bear no tendril or cluster, and the P1-P2 phytomers bear a tendril or a cluster [1]. As previously observed, the succession sequence in all the axes is repetitive (P0-P1-P2) excepted at the base of the primary axis (corresponding to the preformed part of the shoot). In this zone the succession of the phytomers is disturbed and a consensus sequence corresponding to the sequence with the greatest probability [8] observed in natural conditions is forced in the model for both cultivars as follows:

$P 0-P 0-P 0-P 0-P 1-P 2-P 0-P 0-P 1-P 2-(P 0-P 1-P 2) \ldots$

The clusters, if present in the plant, are located on the two first phytomers P1 and P2 on the primary axis. At most two clusters are able to develop on each shoot [1].

Primary axis organogenesis. In well watered condition, the leaf appearance rate on the primary axis was observed to be constant even in situation of severe trophic competition and equal to 0.044 phytomer. $\mathrm{Cd}^{-1}$ [1][8]. This trend allows considering, when there is no water deficit, a constant time step of the model $\left(D_{g c}\right)$ equal to the rhythm of phytomer appearance on the primary axis $\left(23^{\circ} \mathrm{Cd}\right)$. Preliminary studies emphasized the fact that the development does not end in absence of water deficit, even in situation of high level of trophic competition [3]. Thus, in the model, the organogenesis of the primary axis continues with the same leaf appearance rate as long as $Q(i)$ is not equal to 0 .

Secondary axis organogenesis. Five development states of the axillary buds are considered in the model (Fig. 2). In state 0 the bud has not broken out, in state $0-1$ the bud has broken out and is in a transition phase called 'lag period' during which it is not able to produce a leaf. When the bud becomes active three events can occur at each development stage, the bud may produce a leaf (state 1-1), may stay quiescent (state 1) or may die (state 1-0).

In the current version of the model, the probability of budburst occurrence $\left(P_{b}\right)$ (transition from state 0 to state $0-1$ ), is set to 1 except for the two first axillary buds for which $P_{b}$ is set to 0 [8]. Note that these probabilities are fixed in the model at the beginning of plant development and do not change during plant development. The transition from state $0-1$ to state 1 systematically occurs after a constant lag period $\left(d_{l}\right)$. Thus, an axillary bud of insertion rank $j$ on the primary axis, which has broken up, becomes active at the growth cycle $j+d_{l}$ with $d_{l}$ generally equal to $6 G C$. [8] When a bud becomes active, $P_{e}$ corresponds to the probability of an axillary bud to die, $P_{p}$ corresponds to the probability of an axillary bud to produce a leaf and $1-P_{p}$ to its probability to stay alive without producing new leaves (i.e. quiescent).

In previous studies [1][8], differences between leaf appearance rate of $\mathrm{P} 0$ secondary axes and P1-P2 secondary axes were observed. Moreover, the leaf 
appearance rate of the different axes was roughly constant during their development and depended on the trophic competition at their appearance which is represented by $Q(i) / D(i)$ (called afterwards $Q / D$ ). This formalism is implemented in the model by considering that $P_{p}$ depends on the type of secondary axis (i.e physiological age) $(k)$ and on the value of $Q / D$ when the axillary bud becomes active. The probability of a secondary axis of insertion rank $j$ and of type $k$ $\left(P_{p}(j, k, i)\right)$ to produce leaf (state 1-1) at growth cycle $i$ is thus implemented in the model.

$$
P_{p}(j, k, i)=c_{p}(k) \cdot\left(\frac{Q\left(j+d_{l}\right)}{D\left(j+d_{l}\right)}\right)
$$

A consistent correlation between the rate of secondary axes which ended their development $\left(T_{e}\right)$ and the $Q / D$ values at the corresponding growth cycle (i) was observed in previous studies [3]. The sensitivity of secondary axes to trophic competition also depended on the number of leaves on the corresponding axis $(c)$ and on the type of secondary axis (i.e physiological age) $(k)$. Thus, in the model the probability of a secondary axis of type $k$, with number of leaves $c$, of insertion rank $j$, to die at the growth cycle $i\left(P_{e}(j, k, c, i)\right)$ is expressed according to the predicted rate of end of development of secondary axes of type $k$ and of number of leaves $c$ at growth cycle $i\left(T_{e}(k, c, i)\right)$ as follows [3]:

$$
\begin{cases}\text { if } \quad & \left(1-T_{e}(k, c, i)\right) \cdot N_{I I}(k, c, i)<N_{I I, p}(k, c, i) \\ & P_{e}(j, k, c, i)=\left(\frac{N_{I I, p}(k, c, i)-N_{I I}(k, c, i) \cdot\left(1-T_{e}(k, c, i)\right)}{N_{I I, p}(k, c, i)}\right) \\ \text { if } \quad & \left(1-T_{e}(k, c, i)\right) \cdot N_{I I}(k, c, i) \geq N_{I I, p}(k, c, i) \\ & P_{e}(j, k, c, i)=0\end{cases}
$$

with $N_{I I}(k, c, i)$ the total number of secondary axes of type $k$, with a number of leaves $c$ at growth cycle $i . N_{I I, p}(k, c, i)$ is the potential number of secondary axes calculated by considering that no new axillary bud died (state 1-0) at growth cycle $i$.

With [4]:

$$
T_{e}(k, c, i)=1-\frac{1}{1+\exp \left[\frac{-\frac{Q(i)}{D_{p}(i)}+a_{e}(k, c)}{b_{e}(k, c)}\right]}
$$

with $D_{p}(i)$ the potential demand for biomass, calculated by considering that no new axillary bud died (state 1-0) at growth cycle $i$.

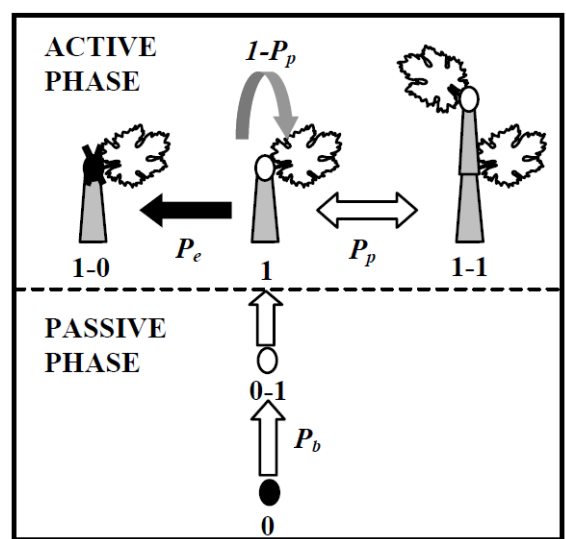

Figure 2: Different states of the axillary buds and transition probabilities.

Photosynthetic production. The photosynthetic production of biomass at each growth cycle $(G C) i$ $\left(Q_{p}(i)\right)$ is implemented in the model using a BeerLambert law production function, previously used for grapevine [3] as follows:

$Q_{p}(i)=\operatorname{PAR}(i) \cdot \operatorname{Sp} \cdot R U E(i) \cdot\left[1-\exp \left(\frac{-k \cdot S(i)}{S p}\right)\right]$

with PAR(i), the photosynthetic active radiation at each growth cycle $\left(\right.$ mol. $\left.m^{-2} \cdot G C^{-1}\right), S p$, the projected leaf area $\left(m^{2}\right), R U E(i)$ the radiation use efficiency at growth cycle $i\left(g . \mathrm{mol}^{-1} . \mathrm{m}^{-2}\right), S(i)$, the total leaf surface at growth cycle $i\left(\mathrm{~m}^{2}\right)$ and $k$ the extinction coefficient for the Beer Law.

Reserve behaviour. During the 'heterotrophic' phase of plant development, from budburst to flowering [9], biomass from reserve may be mobilized. The initial biomass $\left(Q_{r, \text { ini }}\right)$ of reserve is an input of the model at the beginning of plant development. A parameter $\beta_{h}$ describes the part of non-strutural reserve biomass available for shoot development [10]. The time course of reserve mobilization is modelled with a beta function $\left(f_{r}(i)\right)$, and a duration of biomass reserve mobilization $\left(T_{r}(i)\right)$. At each growth cycle $i$ the quantity of biomass in the reserve $\left(Q_{r}(i)\right)$ is calculated as follows:

$Q_{r}(i)=Q_{r}(i-1)-f_{r}(i) \cdot \beta_{h} \cdot Q_{r, i n i}$

During the 'autotrophic' phase (from flowering to maturity) reserve 'storage' and 'mobilization' can both occur [9].

Reserve 'storage' occurs when: $Q_{p}(i)>r$

Reserve 'mobilization' occurs when: $Q_{p}(i) \leq r$

with $c\left(g . G C^{-1}\right)$, an input parameter of the model.

Which could be simplified for young plant [8][10] to $r=0$. 
When reserve 'storage' occurs, the part of biomass allocated to the reserve is estimated from an allometric relationship combining the photosynthetic production to the reserve biomass. A parabolic function is implemented.

$$
Q_{r}(i)=Q_{r}(i-1)+a \cdot Q_{p}(i)^{2}+b \cdot Q_{p}(i)
$$

(9)

When reserve 'mobilization' occurs, a parameter $\beta_{a}$, accounts for the part of biomass that may be mobilizable from the reserve [10]. This parameter allows to estimate the initial available biomass of reserve when the mobilization of reserve begins (during the autotrophic phase), at growth cycle $z$. The fraction of biomass $(\mu)$ that may be mobilized from reserve is considered as constant at each growth cycle. Consequently, we can estimate the quantity of available $\left(Q_{r, a}(i)\right)$ and total $\left(Q_{r}(i)\right)$ reserve biomass as follows:

$$
\begin{aligned}
& Q_{r, a}(i)=\left\{\begin{array}{ccr}
\beta_{a} \cdot Q_{r}(z) \cdot(1-\mu \cdot(i-z+1)) & \text { if } & Q_{r, a}(i-1)>0 \\
0 & \text { else } & \text { (10) }
\end{array}\right. \\
& Q_{r}(i)=\left\{\begin{array}{llr}
Q_{r}(i-1)-\mu \cdot \beta_{a} \cdot Q_{r}(z) & \text { if } & Q_{r, a}(i-1)>0 \\
Q_{r}(i-1) & \text { else } & \text { (11) }
\end{array}\right.
\end{aligned}
$$

with $z$, the growth cycle when reserve mobilization begins.

Biomass allocated to the non-perenial organs $(Q)$. The combination between photosynthetic production and reserve behaviour allows to calculate the part of biomass allocated to the shoot $(Q(i))$. To take into account the part of reserve biomass mobilized from the reserve and really converted into biomass for shoot development a parameter $\alpha$ is implemented in the model [11]

In the 'heterotrophic' phase of plant development:

$Q(i)=Q_{p}(i)+\alpha \cdot f_{r}(i) \cdot \beta_{h} \cdot Q_{r, i n i}$

In the 'autotrophic' phase of plant development.

$$
\left\{\begin{array}{l}
\text { if } Q_{p}(i)>r \\
Q(i)=(1-b) Q_{p}(i)-a Q_{p}(i)^{2} \\
\text { if } Q_{p}(i) \leq r \\
Q(i)=\left\{\begin{array}{cc}
Q_{p}(i)+\alpha \cdot \mu \cdot \beta_{a} \cdot Q_{r}(z) & \text { if } Q_{r, a}(i-1)>0 \\
0 & \text { else }
\end{array}\right.
\end{array}\right.
$$

Biomass allocation between non-perenial organs. In the model biomass allocation processes are separated in two phases, the first phase is a phase of biomass allocation for each growth process (organ expansion, and secondary growth) and the second phase is a phase of allocation between the different organs.

Demand for organ expansion is calculated as already proposed in the GreenLab model [7]. Each organ $(o)$ for each physiological age $(k)$ is defined using a sink strenght $\left(P_{o}(k)\right)$, and a beta law function depending on its chronological age $(n)\left(f_{o}(n)\right)$ and identical for all the physiological ages. For clusters, two phases of development exist, one from flowering to veraison and the other one from veraison to maturity [12]. Therefore two sink strenghts with their own associate beta function are implemented in the model. The total demand for organ expansion at the growth cycle $i\left(D_{\exp }(i)\right)$ is thus defined by:

$D_{\text {exp }}(i)=\sum_{k} \sum_{0} P_{o}(k) \cdot \sum_{n} f_{o}(n) \cdot N_{o}(n, k, i)$

where $N_{o}(n, k, i)$ is the total number of organs of type o, physiological age $k$ and chronological age $n$ in the plant at growth cycle $i$.

The total demand for secondary growth at growth cycle $i\left(D_{s}(i)\right)$ is implemented in the model, according to the total number of leaves $\left(N_{l}(i)\right)$ and using a constant sink strenght $\left(P_{s}\right)$.

$D_{s}(i)=P_{s} \cdot N_{l}(i)$

Thus the total biomass demand $(D(i))$ of the shoot at each growth cycle $i$ can be expressed by [13]:

$D(i)=D_{\exp }(i)+D_{s}(i)$

The part of biomass allocated to organ expansion $\left(Q_{\text {exp }}\right)$ and secondary growth $\left(Q_{s}\right)$ is calculted as a function of the total demand:

$Q_{\exp }(i)=D_{\exp }(i) \cdot \frac{Q(i)}{D(i)} \quad$ and $\quad Q_{s}(i)=D_{s}(i) \cdot \frac{Q(i)}{D(i)}$

The biomass allocated to each organ for its expansion $\left(\Delta q_{o}(n, k, i)\right)$ is given by:

$\Delta q_{o}(n, k, i)=P_{o}(k) \cdot f_{o}(n) \cdot \frac{Q_{\exp }(i)}{D_{\exp }(i)}$

The biomass allocated for secondary growth of the different internode is implemented according to the formalism previously proposed [13], using a flexible submodel of allocation with two modes of allocation, one based on the pipe model theory and the second 
based on a uniform allocation. In the first mode, the biomass allocated for secondary growth of each internode is calculated according to the surface of active leaves above it in the plant topology. In the second mode the surface above the internode is not considered and all the leaves participate equally to secondary growth. The two models are combined with a parameter $\lambda[13]$.

Organ sizes are calculated with allometric relationships between organ masses and sizes. For leaves, individual leaf area $\left(S_{j}(i)\right)$ at each growth cycle is calculated, using a specific leaf weight $(S L W(i))$ which was observed, in previous studies, to be highly correlated to the photosynthetic active radiation (PAR(i) ) [14].

$S_{j}(i)=q_{l, x}(i) / S L W(i)$

With $S L W(i)=a_{l} \cdot \operatorname{PAR}(i)+b_{l}$

Where $q_{l, j}(i)$ is the biomass of the leaf $x$ at growth cycle $i$.

Influence of water status on plant development. The effect of soil water deficit on axis organogenesis was observed to be independent from the decrease in global photosynthetic activity [2][6], due to hormonal signaletic mainly related to ABA influx from roots [6]. However the observed decrease in axis organogenesis depended on the type of axis. Primary axis was less affected than secondary axes, and the different secondary axes (P0 or P1-P2) were affected to the same extend. Thus, as previous observed [2], the water status dependence of the leaf appearance rate is implemented in the model. For primary axis, this trend forces to change the duration of the growth cycle $\left(d_{g c}\right)$, defined as the phyllochrone of the primary axis, and equal to $23^{\circ} \mathrm{Cd}$ in well-watered situation [8]:

$d_{g c}=23 .\left(1+a_{w, I} \cdot \exp \left(+b_{w, I}\left(\operatorname{FTSW}(t)+c_{w, I}\right)\right)\right.$

with $F T S W(t)$ the fraction of transpirable soil water at date $t, a_{w, I}$ $b_{w, I}$ and $c_{w, I}$ three parameters of the sigmoid equation.

The effect of soil water deficit on $P_{p}(j, k, i)$ (we recall that $P_{p}(j, k, i)$ determines at each growth cycle $i$ the probability to produce a leaf for a secondary axis of type $k$ and of insertion rank $j$ ) is implemented as proposed by Lebon et al. 2006 [2]:

$\left.P_{p}(j, k, i)=\left(\frac{1}{1+a_{w, I l} \exp \left(+b_{w, I I}\left(F T S W(i)+c_{w, I l}\right)\right)}\right) \cdot c_{p}(k)\right) \cdot\left(\frac{Q(j+l)}{D(j+l)}\right)$

with $a_{w, I I}, b_{w, I I}$ and $c_{w, I I}$ three parameters of the sigmoid equation.

Radiation use efficiency was observed to be reduced by soil water deficit due to the limitation of $\mathrm{CO}_{2}$ exchange [2]. We define $\alpha_{w}(i)$ as a function of
$F T S W(i)$ to modified $R U E_{\max }$ in situation of soil water deficit at each growth cycle $i[2]$ :

$$
\begin{aligned}
& \text { RUE }(i)=\alpha_{w}(i) \cdot R U E_{\max } \\
& \text { With } \alpha_{w}(i)=\frac{1}{1+6.20 \cdot \exp (-6.36(F T S W(i)+0.14))}
\end{aligned}
$$

\subsection{Experiments used for model parametrization and evaluation.}

Five experiments were carried out at the SupAgroMontpellier-INRA campus in a greenhouse (exps. $3,4,5$ ) and outside (exps. 1\&2) on two grapevine (Vitis vinifera L.) cultivars 'Syrah' and 'Grenache N.' (Table 1). Experiments were managed on three-year-old plants cultivated in pots (diameter $=0.3 \mathrm{~m}$, height $=0.5 \mathrm{~m}$ ), filled with equal proportion of clay, loan and sand. Only one shoot was kept on each plant in exps. 1 to 5 . This shoot was trained vertically during the experiment. All clusters were removed for plants of treatments $\mathrm{T}$ whereas for treatment TG (exp.1), two clusters were retained on the shoot. In these experiments water supplies and fertilization were managed in order to avoid any water or mineral deficiency. A large range of PAR conditions was observed among these experiments ranging from 0 to $53.5 \mathrm{~mol} \cdot \mathrm{m}^{-2} \cdot \mathrm{d}^{-1}$. In exp. 5 , plants were subjected to a mean value of PAR of $12.6 \mathrm{~mol} \cdot \mathrm{m}^{-2} \cdot \mathrm{d}^{-1}$ (Table 1) from budburst to $580^{\circ} \mathrm{Cd}$ and were then placed below a polyester shelter in order to get a complete occultation of incident PAR (Table 1).

\begin{tabular}{|c|c|c|c|c|c|}
\hline Exp. & Treatment & $\begin{array}{c}\text { Duration } \\
\left({ }^{\circ} \mathrm{Cd}\right)\end{array}$ & $\begin{array}{c}\text { Daily mean } \\
\text { temperature } \\
\left({ }^{\circ} \mathrm{C}\right)\end{array}$ & $\begin{array}{l}\text { Daily mean } \\
\text { PAR } \\
\left(\mathrm{mol} \cdot \mathrm{m}^{-2} \cdot \mathrm{d}^{-1}\right)\end{array}$ & $\begin{array}{l}\text { mean } \\
\text { FTSW }\end{array}$ \\
\hline 1 & $\overline{\mathrm{T}}$ & 1158 & 24.4 & 53.5 & - \\
\hline 1 & TG & 1158 & 24.4 & 53.5 & - \\
\hline 2 & $\mathrm{~T}$ & 1128 & 22.6 & 43.6 & - \\
\hline 3 & $\mathrm{~T}$ & 1077 & 21.2 & 12.6 & - \\
\hline 4 & $\mathrm{~T}$ & 1210 & 20.1 & 6.3 & - \\
\hline 5 & $\mathrm{~T}$ & 1166 & 22.4 & 12.6 then 0 & - \\
\hline $6[2]$ & $\mathrm{T}$ & 803 & 23.4 & 54.8 & 0.74 \\
\hline $6[2]$ & $\mathrm{T}$ & 803 & 23.4 & 54.8 & 0.31 \\
\hline $6[2]$ & $\mathrm{T}$ & 803 & 23.4 & 54.8 & 0.18 \\
\hline
\end{tabular}

Table 1: Environmental conditions in the experiments.

The number of leaves on each axis was counted every three days. Axes were distinguished according to their types (primary axis or P0-P1-P2 secondary axis). Roughly, 550, 800 and $1100^{\circ} \mathrm{Cd}$ after budburst, four plants, per treatment were harvested. The sizes and the dry masses of all plant organs including roots were then measured. Allometric relationships were used to estimate individual leaf areas and total leaf area of the plants. 
The data of exp. 6 were extracted from Lebon et al. 2006 [2]. In this experiment, one shoot without cluster was kept on each plant. Three treatments depending on the mean values of FTSW were applied $(0.78,0.31$ and 0.18 ), on these plants (Table 1). The water deficit was applied to the plant $380^{\circ} \mathrm{Cd}$ after budburst. Data about the evolution of total leaf area and of the number of leaves were available whereas no data on plant dry mass were available in this experiment.

\section{Results}

\subsection{Assessments of model simulations}

The estimated values of the different parameters were obtained from the determinist version of GreenLab by model inversion, from experimental data and from literature. Model inversion of GreenLab model was used to estimate the sink strengths and the associated beta functions for all the organs, the parameters of the relationships between $Q / D$ and axis development and the parameters of the production equation. These parameters, largely exposed in Pallas et al. 2009 [3], were obtained on an independent set of plants. Litterature was used to estimate the parameters of the phyllochron [1][8], and the parameters of secondary axis development according to soil water deficit [2]. Measurements were used to estimate the parameters of reserve behaviour and the parameters of the relationship between SLW and PAR. A unique set of constant parameters was used for all experiments, and the number of clusters on each plant was an input of the model. Only the environmental data changed among the experiments (Table 1). The obtained simulations results were then confronted to the experimental measurements.

The results presented in this section are only the results of simulations made on 'Grenache N.', as the results of 'Syrah' are quite similar (data not shown). The simulations of organogenesis processes on plants are consistent with the observed values for the experiment carried out outside, in the greenhouse (Fig. $3)$. The model simulates well the variations of axis development, due to the modular structure of the shoot (P0-P1-P2) and due to the differences in axis behaviour related to their insertion rank [1]. Moreover the model reproduces the decrease of the number of leaves on the secondary axes in accordance with the decrease of incident PAR in the greenhouse (Fig. 3B).

At the whole plant level the model is strongly consistent with observed values for the six experiments (Fig. 4). The variable with the lowest RRMSE is the total leaf area $(12.2 \%)$ and with the greatest is total dry mass $(22.1 \%)$. Note also that the dynamics of biomass growth of clusters (Fig. 4D) is quite similar with others observed dynamic in previous studies [3].

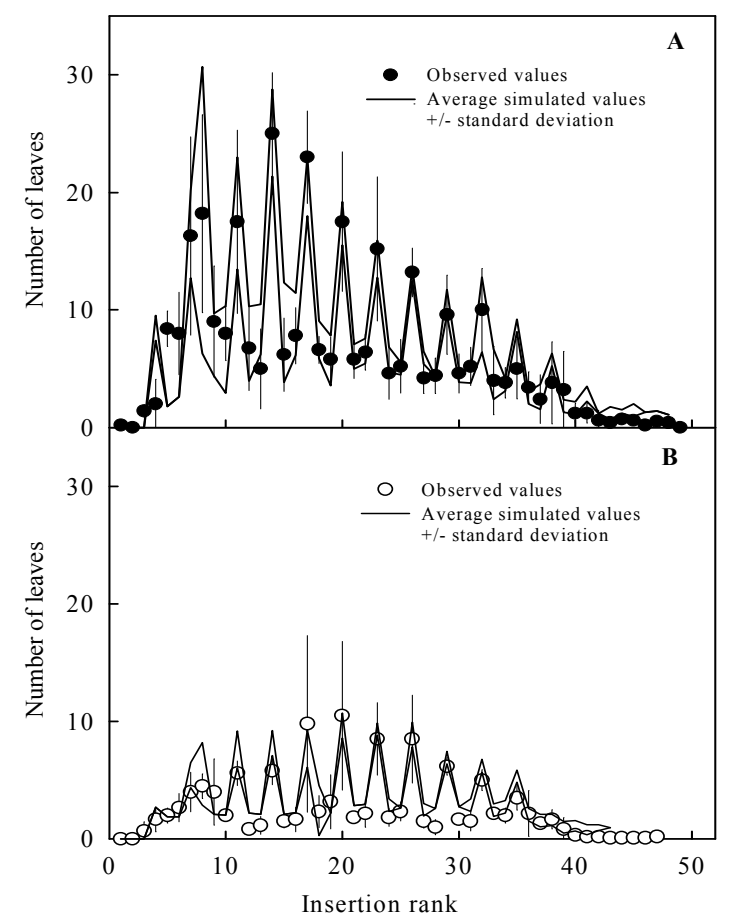

Figure 3. Observed and simulated values of the final number of leaves on each secondary axis according to their insertion rank on the primary axis. Simulation results in exp. 1 with the plants of TG treatment (A). Simulation results in exp. 3 (B). Simulation standard deviations were calculated with 50 repetitions of the adjustment procedure. Bars indicate the standard deviation of the observed values.

\subsection{Evolution of the trophic competition in the various experiments.}

The evolution of the $Q / D$ ratio and its absolute values are consistent with the available data previously obtained by GreenLab model inversion on grapevine [3] (Fig. 5).

In outside experiments for plants without clusters (T) (Fig. 5A, exps. 1\&2), after a first decrease at the beginning of shoot development, the $Q / D$ ratio tends to increase due to the increase of the number of autotrophic organs. Then, $Q / D$ decreases in relation with the increase of the number of developing axes and of internode secondary growth [3]. 


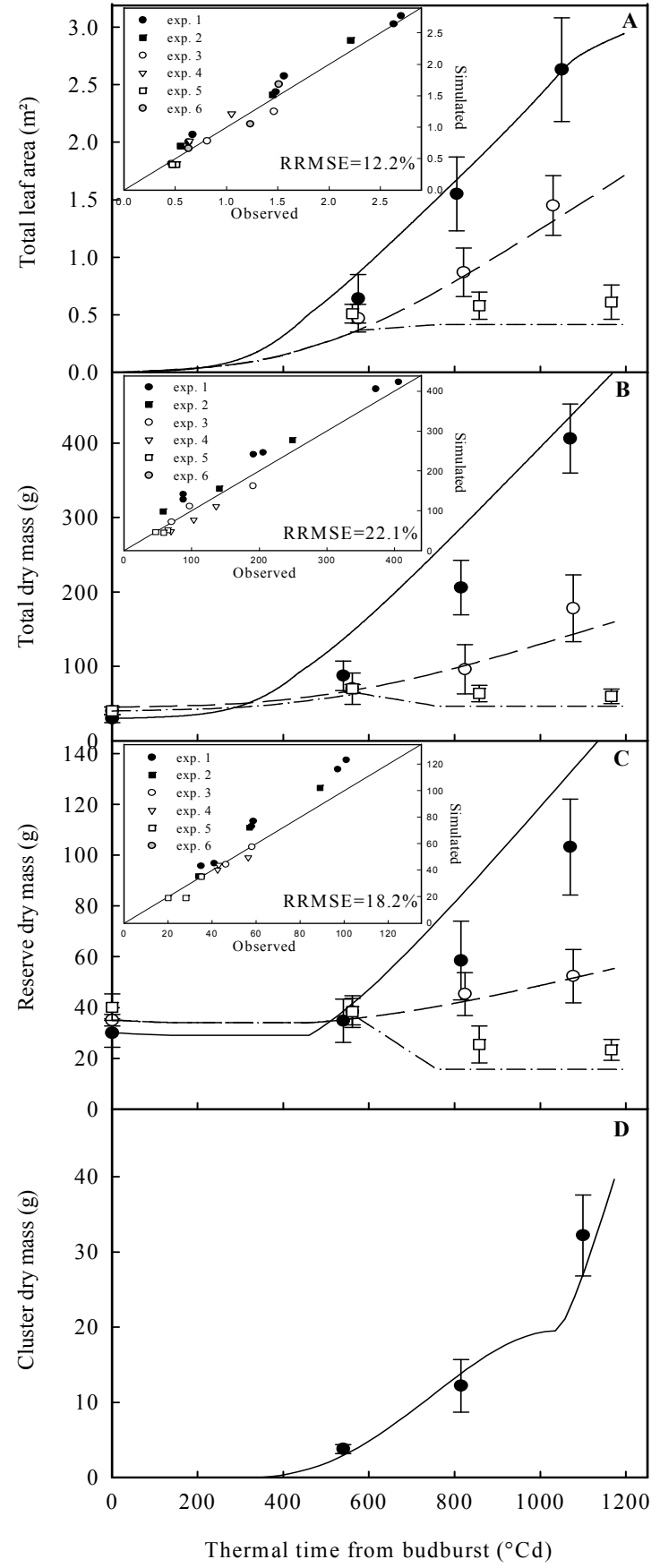

Figure 4. Evolution of total leaf area (A), total dry mass (B), reserve dry mass $(C)$ and clusters dry mass (D) for the plants of exp. 1 (TG) of exp. 3 and 5. The symbols represent the observed values and the solid or dashed lines the simulated values. Bars indicate the standard deviation of the observed values. The inserts represent the comparison between the observed and the simulated values for the whole dataset.

The decrease of incident PAR in the greenhouse (Fig. 5A, exps. 3, 4\&5) tends logically to decrease the
$Q / D$ ratio, which appears to stabilize, with no other observed decrease after $400^{\circ} \mathrm{Cd}$ because the number of developing axes and secondary growth are limited.

The presence of clusters tends to decrease the $Q / D$ ratio particulary after $1100^{\circ} \mathrm{Cd}$ (veraison stage, Fig. $5 \mathrm{~B}$ ) corresponding to the phase of the greatest increase of cluster growth rate [12] whereas the effect of cluster development before this date is really weak.

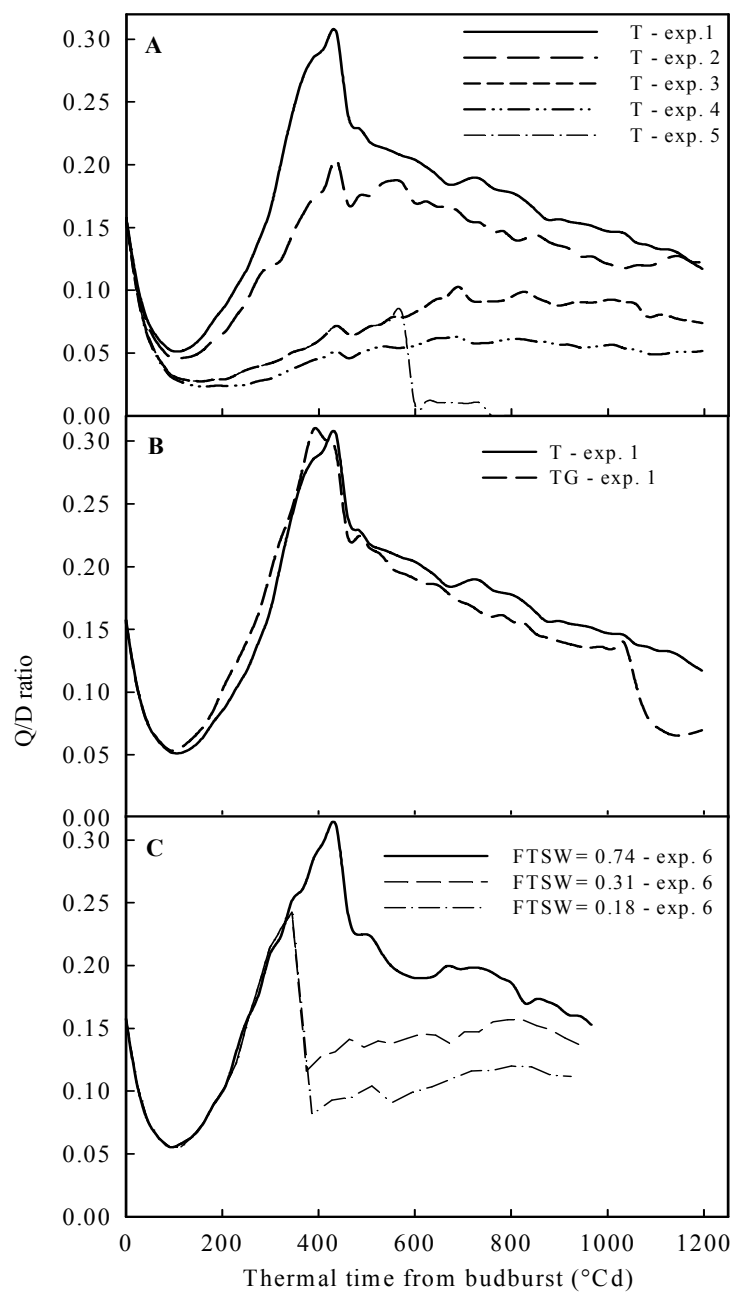

Figure 5. Evolutions of the $Q / D$ ratio according to thermal time. in exps. 1 to 5 with $T$ treatments $(A)$, in exp. 1 with $T$ and TG treatments $(\mathrm{B})$ and in 6 exp. $6(\mathrm{C})$.

Soil water deficit also decreases the values of $Q / D$, but no decrease of $Q / D$ ratio is observed after $450^{\circ} \mathrm{Cd}$ contrary to what is observed for well-watered plants (Fig 5C). Even a slight increase in $\mathrm{Q} / \mathrm{D}$ ratio is observed after $450^{\circ} \mathrm{Cd}$ for the plants in soil water deficit. This observation is consistent, with a decrease of the competition among the vegetative sinks in situation of water deficit [2]. 


\subsection{Sensitivity analysis}

The model was extensively tested for its sensitivity to input variables, in order to explore its behaviour and evaluate the biological coherence of its response. In the present study, one sensitivity analysis illustrates the impact of FTSW (Fig. 6) variations on the model outputs. Concerning the effect of FTSW, the model reproduces an observed pattern with potential repercussions on agronomic practices. Cluster dry mass appears to be the least affected by soil water deficit. A significant decrease of cluster dry mass is only observed for FTSW values lower than 0.35 , whereas for the other variables, this decrease is observed for values lower than 0.60 [15]. This observation probably results from the decrease of the number of vegetative 'sinks' due to the signaletic regulation of vegetative development, which leads to promote cluster development in situations of moderate soil water deficit.

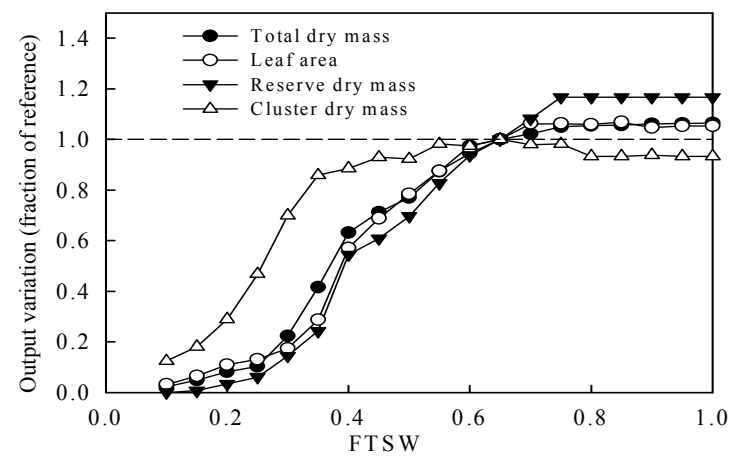

Figure 6. Sensitivity analysis of various model outputs to different values of FTSW. All model outputs were normalized according to the values observed at FTSW $=0.7,1200^{\circ} \mathrm{Cd}$ after budburst with PAR $=40 \mathrm{~mol} \cdot \mathrm{m}^{-2} \cdot \mathrm{d}^{-1}$.

\section{Conclusions-perspectives}

This study is a first attempt to simulate real plant development using the principles of retroaction between plant organogenesis, morphogenesis and trophic competition developped with the GreenLab model [7][13]. The $Q / D$ ratio appears as a relevant variable to drive plant development in fluctuating environment, including soil water deficit. This new version of the model using the main principles of GreenLab model with stochastic rules of axis development according to trophic competition appears promising to further simulate plant population development in various environments.

\section{References}

[1] B. Pallas, G. Louarn, A. Chritophe, E. Lebon and J. Lecoeur. Influence of intra-shoot trophic competition on shoot development of two grapevine cultivars (Vitis vinifera L.). Physiologia Plantarum. 2008 134: 49-63.

[2] E. Lebon, A. Pellegrino, G. Louarn and J. Lecoeur. Branch development controls leaf area dynamics in grapevine (Vitis vinifera L.) growing in drying soil. Annals of Botany. 2006 98: 175-185.

[3] B. Pallas, A. Christophe, P.H Cournède and J. Lecoeur. Using a mathematical model to evaluate the trophic and non trophic determinants of axis development in grapevine. Functional Plant Biology. 2009. 36: 156-170.

[4] M. Rives. Vigour, pruning, cropping in the grapevine (Vitis vinifera L.). Agronomie. 2000. 20: 79-91.

[5] R.M. Stevens, J.M. Pech, M.R. Gibberd, R.R. Walker, J.A. Jones, J. Taylor and P.R. Nicholas. Effect of reduced irrgation on growth, yield, ripening rates and water relations of Chardonay vines grafted to five rootstocks. Australian Journal of Grape and Wine Research. 2008. 14: 177-190.

[6] W.J. Davies and J. Zhang. Root signals and the regulation of the growth and development of plants in drying soil. Annual Reviews of Plant Physiology and Plant Molecular Biology. 1991. 42: 55-76.

[7] A. Mathieu, PH Cournède, V. Letort, D. Barthélémy and P. De Reffye. A dynamic model of plant growth with interactions between development and fucntional mechanisms to study plant structrual plasticity related to trophic competition. Annals of Botany. 2009. 103: 11731186.

[8] G. Louarn, Y. Guédon, J. Lecoeur and E. Lebon. Quantitative analysis of the phenotypic variability of shoot architecture in two grapevine cultivars (Vitis vinifera L.). Annals of Botany. 2007. 99: 425-437.

[9] W. Koblet, P. Perret.Wanderung von assimilaten innerhalb der rebe. Wein-Wiss. 1969. 24: 277-319.

[10] M. Keller, B. Hess, H. Schwager, H. Schärer and W. Koblet. Carbon and nitrogen partitioning in Vitis vinifera L.: Responses to nitrogen supply and limiting irradiance. Vitis 1995. 34. 19-26.

[11] P.H. Vivin, M. Castelan, J.P. Gaudillière. Seasonal changes in chemical composition and construction costs of grapevine tissues. Vitis. 2003. 42:5-12.

[12] B.G. Coombe. The development of fleshy fruits. Annual Review of Plant Physiology. 1976. 27: 207-228

[13] V. Letort, PH Cournède, A. Mathieu, P. De Reffye and T. Constant. Parametric identification of a functionalstructural tree growth model and application to beech trees. Functional Plant Biology. 2008. 35: 951-968.

[14] D. Mezziane and B. Shipley. 1999. Interacting determinants of specific leaf area in 22 herbaceous species: effects of irridiance and nutrient availability. Plant Cell and Environment. 1999. 22: 447-459.

[15] A. Carbonneau, A. Deloire and B. Jaillard. La vigne, physiologie, terroir, culture, Dunod, Paris, 2007. 